\title{
Effect of graphite sizes and carbon black content on flowability of the injection molded conductive composite material
}

\author{
Yovial Mahyoedin ${ }^{1 *}$, Jaafar Sahari ${ }^{2}$, Andanastuti Mukhtar ${ }^{2}$, Norhamidi Mohammad $^{2}$ and \\ Suryadimal $^{1}$ \\ ${ }^{1}$ Dept of Mechanical Engineering, Bung Hatta University, Padang, Indonesia \\ ${ }^{2}$ Dept. of Mechanic and Materials Engineering, Faculty of Engineering \& Built Environment \\ Universiti Kebangsaan Malaysia, 43600 UKM Bangi, Malaysia
}

\begin{abstract}
This study is to investigate the flowability of the injection molded conductive composite material containing filler content from 70 up to $80 \mathrm{wt} \%$ by using spiral mold. Several moulding compounds, containing polypropylene (PP) as a matrix and graphite $(\mathrm{G})$ and carbon black $(\mathrm{CB})$ as conductive fillers prepared by melt compounding using twin-screw extruder. Carbon black is added as much as $10 \%$ and $20 \%$ respectively, in order to improve the electrical conductivity of composite material. Results show that the flowability of injection molded conductive composite material decreases with decreasing graphite size and with increasing filler (graphite and carbon black) content. It was found that composites containing $\mathrm{G}$ with particle size distribution $(\leq 100 \mu \mathrm{m})$ entirely exhibits a relatively higher flowability, in the range of $10.67-6.21 \mathrm{~cm}$, compared to the small size $(25-60 \mu \mathrm{m})$, in which flowability is in the range of $5.23-3.37 \mathrm{~cm}$. An attempt to combine carbon black as second filler with the PP and $\mathrm{G}$ found that composites containing $\mathrm{CB}$ showed decreased flowability of the injection molded conductive composite material, especially when the electrical conductivity formed through the resin. Results indicate that the flowability of the injection molded conductive composite material is an important design parameter to fabricate cost-effective, large, or thin composite bipolar plates.
\end{abstract}

\section{Introduction}

It has already known that the electrical properties of polymer composite material mainly depend on the dispersion condition of filler particles, particle size and aggregate structure [1]. High filler loading $(>60 \mathrm{wt} \%)$ is needed to provide the required electrical conductivity [2]. Whilst, many authors identified that injection molding is the most promising technology for manufacturing parts of conducting composite [3], because it has multiple advantages over other methods of plastic molding. Not only is plastic injection molding simpler and more reliable, it is also extremely efficient. However, thermosetting polymers are generally more expensive to mold than thermoplastics and represent only about $5 \%$ of plastics processing [4].

\footnotetext{
* Corresponding author: jmahyoedin@yahoo.com
} 
Whilst, the major difficulty in using injection molding is its inability to handle materials with poor flow characteristics [5]. Some literatures have recently compared the effect of graphite size [6] and filler on composite properties.

This study investigates the flowability effect of $\mathrm{PP} / \mathrm{G} / \mathrm{CB}$ material with different graphite contents, graphite particle sizes and the carbon black contents on the formability of the composite bipolar plate

\section{Experimental}

Graphite (G) type Asbury 3243 varied of $25-60 \mu \mathrm{m}$ and $\geq 100 \mu \mathrm{m}$, and carbon black (CB) type Asbury 5303 with particle size of $30 \mathrm{~nm}$ from Asbury Graphite Mills Inc. used as conductive fillers. Polypropylene (PP) random copolymer grade TitanPro SM 688, in the form of granular from Titan Petchem Sdn. Bhd, selected as matrix phase for the different composite formulations.

$\mathrm{CB} / \mathrm{G}$ mixture has a composition ratio, respectively were $20 / 80(20 \% \mathrm{CB}$ and $80 \% \mathrm{G})$ and $10 / 90(10 \% \mathrm{CB}$ and $90 \% \mathrm{G})$. This mixture powder were used as the conductive phase in the range of 60-80 wt.\% and then mixed with PP using ThermoHaake Rheomix Polylab type 557-5501 co-rotating intermeshing twin-screw extruder with temperature of $200^{\circ} \mathrm{C}$. The extrudate immediately cooled in water bath then pelletized using Centurion Guard Master. Approximately $1.5 \mathrm{Kg}$ of each formulation being collected. All types of sample are tabulated in Table 1.

Tabel 1. Name code of specimens and their contents

\begin{tabular}{cclcc}
\hline \multirow{2}{*}{ No } & \multirow{2}{*}{ Names } & \multicolumn{3}{c}{ Content } \\
\cline { 3 - 5 } & & \multicolumn{1}{c}{ Graphite size $(\mu \mathrm{m})$} & Carbon black & Total Filler \\
\hline 1 & CC1 & $100 \%(25-60 \mu \mathrm{m})$ & Non & $60-80 \%$ \\
2 & CC2 & $100 \% \geq 100 \mu \mathrm{m})$ & Non & $60-80 \%$ \\
3 & CC3 & $90 \%(25-60 \mu \mathrm{m})$ & $10 \% \mathrm{wt}$ & $60-80 \%$ \\
4 & CC4 & $80 \%(\geq 100 \mu \mathrm{m})$ & $20 \% \mathrm{wt}$ & $60-80 \%$ \\
5 & CC5 & $90 \%(25-60 \mu \mathrm{m})$ & $10 \% \mathrm{wt}$ & $60-80 \%$ \\
6 & CC6 & $80 \%(\geq 100 \mu \mathrm{m})$ & $20 \% \mathrm{wt}$ & $60-80 \%$ \\
\hline
\end{tabular}
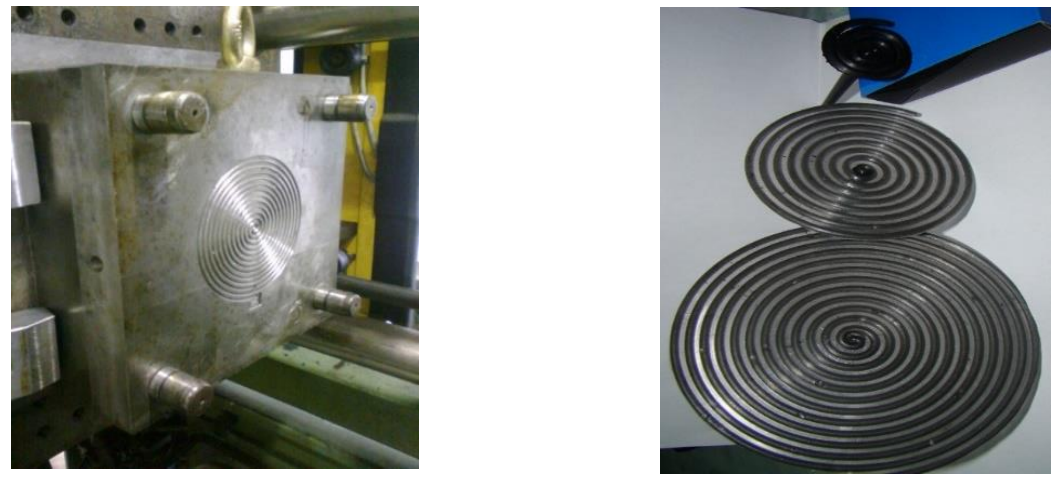

Fig 1. a) Spiral mold and b) Resulting samples, generated from a variety of compositions

Test specimens formed using an Arburg Allrounder 28 ton model 221-55-250 injection molding with a 22-mm diameter single screw. The flowability was determined by means of injection molding of the constant weight of feedstcok material injected into a spiral channel mold. Spiral mold has a groove circle with a diameter of $3 \mathrm{~mm}$ and a depth of $1.5 \mathrm{~mm}$. Figure. 
1 shows the spiral mold and the actually forming shapes generated from a variety of compositions.

Injection molding process parameters are taken as follow: injection pressure varies from 100 to $150 \mathrm{Bar}$, whilst a mold temperature $\left(30^{\circ} \mathrm{C}\right)$ and screw speed $(200 \mathrm{rpm})$ were kept constant. The cooling time in the mold was 110 second, and the holding time was $8 \mathrm{~s}$. The injection molded composites were produced with loadings of 70 and $80 \mathrm{wt} \%$ filler (i.e. mixture of $\mathrm{G}$ and $\mathrm{CB}$ ). The zone temperatures varied according to the PP base composite, progressing from the solids conveying zone $\left(220^{\circ} \mathrm{C}\right)$ to the nozzle zone $\left(230^{\circ} \mathrm{C}\right)$.

\section{Results and discussion}

\subsection{The effect of graphite size on the flowability of material}

Figure 2 plots the flowability of conducting composite material as a function of graphite particle sizes. The flowability trend is almost linear and decreases continuously with increasing graphite content, whereas, for the size of the graphite particles shows that the smaller the particles the shorter the length of the spiral mold.

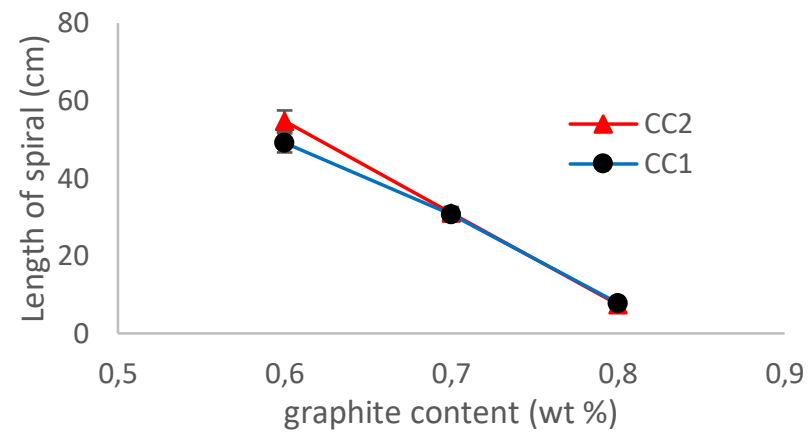

Fig 2. The flowability of conductive composite material PP/G/CB

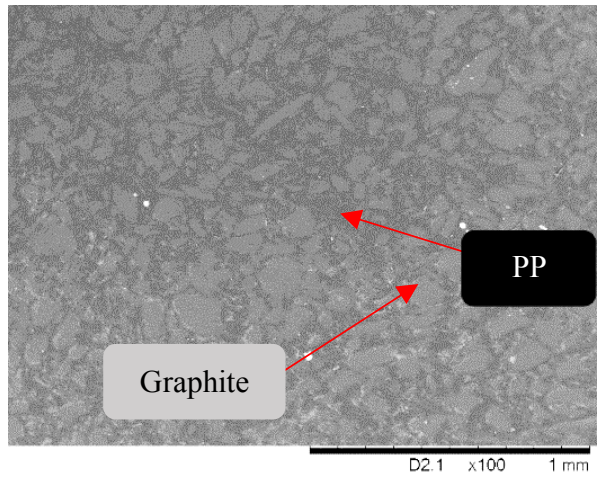

(a)

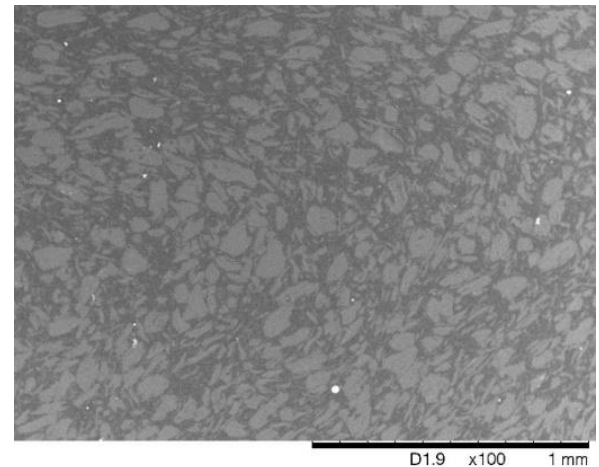

(b)

Fig 3. Optical micrographs of conductive composite $\mathrm{PP} / \mathrm{G} / \mathrm{CB}$, with different graphite sizes (a) $70 \% \mathrm{wt}$ of $\geq 100 \mu \mathrm{m}$, (b) $70 \%$ wt of $25-60 \mu \mathrm{m}$.

Figure 3 (a) and (b) also shown a different size of 70\% wt graphite particles, i.e 25-60 $\mu \mathrm{m}$ and $\geq 100 \mu \mathrm{m}$, respectively. At low graphite content, the particles will separate properly in the media because of the potential power of their rejection. In this case, the interaction between the particles is small and since the $\mathrm{PP} / \mathrm{G}$ conductive material contain higher PP 
content, its serve as lubricant to decrease friction among graphite particles, leading decreased viscosity and consequently, affecting the length of spiral. At high powder loading, the particles will come into contact with one another and tend to agglomerate and to improve the interaction between particles [13]. The finer the powder particles, the easier the formation of agglomerates, the more difficult the occurrence distribution (or dispersion) of the particles. Therefore, the thermoplastic PP surrounding graphite particles cannot penetrate easily; hence, the conductive composite material becomes too sticky to flow smoothly, consequently affecting the length of spiral.

\subsection{The effect of carbonblack on the flowability of material}

The use of graphite powder as main electrical conductivity material and carbon black as second filler was found capable of forming a conductive network between the filler powders [7]. Carbon black also has a double percolation that can increase the electrical conductivity of the material [8]. Several researches have found that the rheological properties of CB composite are affected by CB dispersion throughout the thermoplastic. Viscosity of material increases with increasing CB content. However, the porous structure of carbon black can degrade the mechanical properties. Therefore the powder loading of carbon black as filler in a polymer matrix is limited [9].

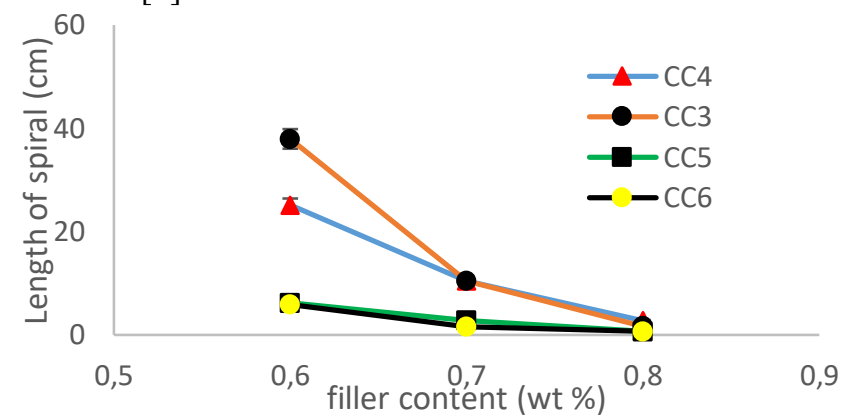

Fig. 4. The flowability of conductive composite material $\mathrm{PP} / \mathrm{G} / \mathrm{CB}$, with different graphite particle sizes, different carbon black content and various composition of filler
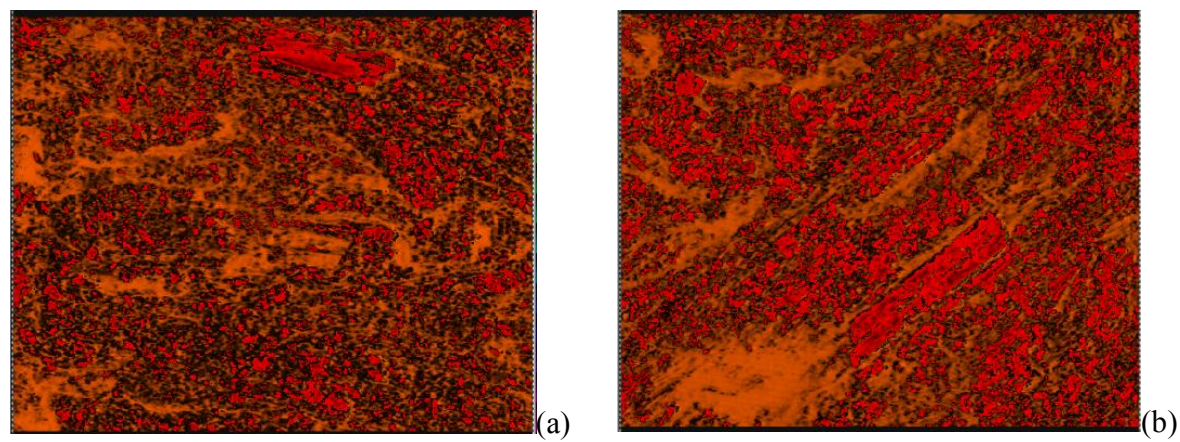

Fig 5. Infrared micrographs of conductive composite $\mathrm{PP} / \mathrm{G} / \mathrm{CB}$, with different carbon black content. (a) $10 \%$ wt CB, (b) $20 \%$ wt CB

Fig. 4 illustrates the flowability of conductive composite material PP/G/CB with 10 and $20 \%$ wt $\mathrm{CB}$ as a function of filler content. The figure shows that flowability of conductive composite material decreases with increasing CB content, i.e. from 25.16 to $1.6 \mathrm{~cm}$ for $20 \%$ wt $\mathrm{CB}$ and from 37.9 to 2.7 for $10 \%$ wt $\mathrm{CB}$. However, the difference flowability of 
conductive composite material looks not significant at very high filler content $(80 \mathrm{wt} \%$ of filler). This implies that critical powder loading of $\mathrm{PP} / \mathrm{G} / \mathrm{CB}$ material is likely to be in the range of $80 \%$ wt of filler. However, an inhomogeneous distribution of the PP throughout the injection molded $\mathrm{PP} / \mathrm{G} / \mathrm{CB}$ samples is probably the main reason. The low PP content of the $\mathrm{PP} / \mathrm{G} / \mathrm{CB}$ composite material confirmed by infrared micrographs observations (Figure 5). One should consider some improvements in order to carry out the processing of conductive material at the very higher filler content.

\section{Conclusions}

The present researches have used various graphite particle sizes, graphite contents, and carbon black contents to analyze the effect of flowability on the production of conductive composite material. In this paper, experimental study of the flowability in injection molding machine is presented in term of length of a spiral molding. Although the production of polymer composite plates by means of injection molding can be troublesome, there has been success in producing plates, depending on the fillers and additives. Results indicate that the flowability of material affected by graphite particle content and size. With decreasing graphite particle size, accumulation density increases and causes the particles will come into contact with one another and tend to agglomerate, thus the thermoplastic cannot penetrate between graphite particles to form a continuous flow channel. The flowability of material also decreases with adding carbon black content. The finer the powder particles, the easier the formation of agglomerates, the more difficult the particles to flow. It has been stressed that homogeneous composite, which contains the maximum filler loading and without sacrificing the ease of molding, should be used in the injection molding mixing step as this will maximize electrical conductivity. Hence, from this study, conductive composite with amount of a second filler of $20 \%$ wt CB was the most suitable filler loading

\section{References}

1. Yovial M., Sahari J., A., Mukhtar, Norhamidi M.: Advanced Materials Research . 233 2353057 (2011)

2. Minkook K., J. Choe, Jun W. L., Dai G. L. Composite Structures. 132, P. 1122-1128 (2015).

3. Boothroyd, G., Dewhurst, P., Knight, W. in: Product design for manufacture and assembly. Marcel Dekker. (2002)

4. Heinzel, A., Mahlendorf, F., Niemzig, O., Kreuz, C. J. Power Sources, 131 35-40 (2004).

5. H.C. Kuan, C.C.M. Ma, K.H. Chen, S.M. Chen: J. Power Sources. 1347 (2004).

6. Dweiri, R. \& Sahari J. Composites Science and Technology. 68:1679-1687 (2008)

7. Tchoudakov, R., M. Narkis, and A. Siegmann : Polymer Engineering \& Science 443:528-540 (2004)

8. Lee, Shuo-Jen, Jian-Jang Lai, and Ching-Han Huang. J. Power Sources 145-2 362-368 (2005):

9. Barrie CL, Griffiths PC, Abbott RJ, Grillo I, Kudryashov E, Smyth C. : J. Colloid Interface Sci. 272(1):210-7. (2004). 